\title{
CIANAMIDA HIDROGENADA NO RALEIO QUÍMICO DE FLORES E FRUTOS DE PESSEGUEIROS (Prunus persica, L. Batsch) CV. ELDORADO
}

\author{
HYDROGEN CYANAMIDE ON CHEMICAL THINNING OF PEACH-TREE \\ (Prunus persica, L. Batsch) FLOWERS AND FRUITS OF ELDORADO CULTIVAR
}

\author{
Alexandre Couto Rodrigues ${ }^{1}$, Valdecir Carlos Ferri ${ }^{1}$, Elisane Schwartz ${ }^{2}$, José Carlos Fachinello ${ }^{3}$
}

RESUMO

$O$ trabalho foi realizado com o objetivo de avaliar o efeito da cianamida hidrogenada $\left(\mathrm{CH}_{2} \mathrm{~N}_{2}\right)$ no raleio de flores $e$ frutos de pessegueiros do cultivar Eldorado. Utilizaram-se plantas com idade de 6 anos, conduzidas sob a forma de vaso e espacamento de 6,0 × 4,0m, localizadas no Centro Agropecuário da Palma - UFPel. Os tratamentos $(0 ; 0,15 ; 0,3 ; 0,45$ e $0,6 \%$ de $\mathrm{CH}_{2} \mathrm{~N}_{2}$ ) foram pulverizados em cobertura sobre ramos selecionados aleatoriamente, até o início de gotejamento, quando $100 \%$ das flores encontravam-se totalmente abertas. $O$ produto comercial utilizado foi o Dormex $\left(52 \%\right.$ de $\left.\mathrm{CH}_{2} \mathrm{~N}_{2}\right)$. $\mathrm{O}$ delineamento experimental foi o inteiramente casualizado, com três repetições. As variáveis avaliadas foram: percentual de flores raleadas 36 dias após a aplicação do produto e percentual de frutos raleados, peso médio, coloração, diâmetro, firmeza da polpa e sólidos solúveis totais por ocasião da colheita. A maior intensidade de raleio de flores $(50,96 \%)$ foi obtida com utilização de 0,5\% de $\mathrm{CH}_{2} \mathrm{~N}_{2}$. Na percentagem de frutos raleados, observou-se valor máximo de $9,53 \%$, utilizando-se $\mathrm{CH}_{2} \mathrm{~N}_{2}$ a $0,6 \%$. O peso dos frutos aumentou com o raleio químico, porém, este não interferiu nos sólidos solúveis totais, firmeza de polpa e índice de cor dos frutos.

Palavras-chave: raleio, pêssego, cianamida hidrogenada.

\section{SUMMARY}

The objective of this research was to evaluate the effect of hydrogen cyanamide $\left(\mathrm{CH}_{2} \mathrm{~N}_{2}\right)$ on the chemical thinning of peach-tree flowers and fruits of Eldorado cultivar. Six-year plants localized at Agricultural Center of Palma - UFPel were used and conducted in vase with spacing of $6.0 \times 4.0 \mathrm{~m}$. Treatments with $0,0.15,0.3,0.45$ and $0.6 \%$ of $\mathrm{CH}_{2} \mathrm{~N}_{2}$ were sprayed on randomly selected shoots until drip point, when $100 \%$ of the flowers were totally blown. Dormex (52\% of hydrogen cyanamide) was the commercial chemical used. A completely randomized experimental design was used, with three replications. Percentage of flowers thinned 36 days after

\begin{abstract}
chemical application and percentage of thinned fruits, mean fruit weight, color, diameter, flesh firmness and total soluble solids at harvest time were evaluated. It was observed statistical difference among treatments on the thinning of flowers. The use of $\mathrm{CH}_{2} \mathrm{~N}_{2}$ $0.5 \%$ showed high intensity of thinning (50,96\%). Differences were also observed for the percentage of thinned fruits, however, the highest thinning was reached at $9.53 \%$ of $\mathrm{CH}_{2} \mathrm{~N}_{2} 0.6 \%$. Fruit weight increased with chemical thinning, however, no changes in total soluble solids, color and fruit flesh firmness were observed.
\end{abstract}

Key words: thinning, peach, hydrogen cyanamide.

\section{INTRODUÇÃO}

A cultura do pessegueiro (Prunus persica, L. Batsch) apresenta grande importância nacional e mundial. No Brasil, é explorada visando à produção de frutos para consumo in natura e também para o processamento industrial. A área cultivada, no Brasil, é de 20 mil hectares, sendo mais de $75 \%$ no Estado do Rio Grande do Sul. A produção anual brasileira é de aproximadamente 100 mil toneladas, destinando-se 57\% para o consumo in natura e $43 \%$ para a industrialização (MAIA et al., 1996).

A produtividade média é de 6,5t/ha, no Rio Grande do Sul (EMBRAPA, 1990), sendo considerada extremamente baixa, tendo em vista a potencialidade do material genético existente e a alta produtividade alcançada por alguns produtores. Várias causas podem estar envolvidas na baixa produtividade, entre elas a poda e raleio inadequados, falta de limpeza dos pomares, adubação desequilibrada, tratamentos fitossanitários deficientes. Tanto os

\footnotetext{
${ }^{1}$ Engenheiro Agrônomo, doutorando em Agronomia, Universidade Federal de Pelotas (UFPEL), Pelotas, RS

${ }^{2}$ Engenheiro Agrônomo, mestranda em Agronomia, UFPEL, Pelotas, RS

${ }^{3}$ Engenheiro Agrônomo, Dr., Professor Titular, FAEM/UFPEL, C. P. 354, 96001-015, Pelotas, RS. Autor para correspondência. Recebido para publicação em 27.03.98. Aprovado em 09.12.98.
} 
cultivares de mesa como os de indústria apresentam um sério inconveniente que é a demasiada carga de frutos, resultando em produção de baixa qualidade e danos às árvores (MARODIN et al., 1994).

Uma prática indispensável na obtenção de produção de qualidade é o raleio de frutos, sendo maior o efeito quanto mais cedo for realizado. $\mathrm{O}$ tamanho do fruto é uma das características mais importantes do pêssego para a industrialização, dada a sua influência no rendimento e custo final de produção da conserva (SACHS \& RHEINGANTZ, 1967).

O raleio pode ser feito de forma manual ou com auxílio de produtos químicos, entretanto, se for realizado manualmente necessita de excessiva mãode-obra em curto período de tempo, tornando-se uma prática onerosa. $\mathrm{O}$ raleio químico de flores de pessegueiros, resulta em $20-30 \%$ de acréscimo no tamanho dos frutos, quando comparado ao raleio manual realizado 40-50 dias após a plena floração (BYERS, 1989).

Em trabalhos realizados com os cultivares Chiripá e Premier, MARODIN et al. (1989) e MARODIN et al. (1991) identificaram a viabilidade de utilização da cianamida hidrogenada como compensador de frio e raleador de gemas floríferas. Segundo MARODIN (1994), os produtos químicos mais utilizados como raleantes são o tiossulfato de amônio (ATS), o etefon, fertilizantes (uréia), surfactantes, herbicidas e a cianamida hidrogenada, entre outros.

Este experimento foi realizado com o objetivo de avaliar o efeito de diferentes concentrações de cianamida hidrogenada no raleio de gemas florais e na qualidade dos frutos de pessegueiros do cultivar Eldorado.

\section{MATERIAL E MÉTODOS}

O experimento foi conduzido no pomar do Centro Agropecuário da Palma, da Universidade Federal de Pelotas, no período de setembro de 1996 a janeiro de 1997. O local possui latitude Sul 31 ${ }^{\circ}$ $41^{\prime}$, longitude $52^{\circ} 21^{\prime}$ Oeste e altitude $93,5 \mathrm{~m}$. O clima é tido como temperado úmido. A classificação do solo predominante é do tipo Podzólico Brunizen. Utilizaram-se plantas de pessegueiros da cv. Eldorado com idade de 6 anos, conduzidas sob a forma de vaso e espaçamento de $6,0 \times 4,0 \mathrm{~m}$.

Os tratamentos consistiram na pulverização de $0,0,0,15,0,3,0,45$ e $0,6 \%$ de cianamida hidrogenada $\left(\mathrm{CH}_{2} \mathrm{~N}_{2}\right)$ no dia dois de setembro de 1996, em ramos sorteados. Previamente, contou-se o número de gemas florais, anotando-se o estádio fenológico (100\% das gemas estavam no estádio F), de acordo com a escala de FLECKINGER (1954). O produto foi pulverizado em cobertura até o ponto de gotejamento, com o uso de um pulverizador costal. O produto comercial utilizado foi o Dormex (52\% de cianamida hidrogenada). O delineamento experimental foi o inteiramente casualizado, com três repetições, perfazendo-se um total de 15 parcelas experimentais.

A percentagem de flores raleadas foi avaliada no $36^{\circ}$ dia após a aplicação dos tratamentos, comparando-se o número de flores e/ou frutinhos com a contagem inicial do número de flores (subtraindo-se o raleio natural). A percentagem de frutos raleados foi avaliada na colheita dos frutos (03 de janeiro de 1997), comparando-se o número de frutos colhidos com o número inicial de flores (descontando-se o raleio natural).

Determinaram-se também o peso médio dos frutos colhidos, cor dos frutos (notas de 1 a 5, sendo 1 para os frutos que se apresentavam em estado mais verde e 5 para os frutos em estado maduro na colheita), diâmetro médio dos frutos (medida da secção equatorial do fruto com auxílio de um paquímetro), firmeza de polpa (através do uso de penetrômetro de ponteira $8 \mathrm{~mm}$, tomada na região equatorial dos frutos) e sólidos solúveis totais (expresso em ${ }^{0}$ Brix, com refratômetro de mão).

Para verificar o nível de significância estatística dos efeitos das concentrações da cianamida hidrogenada em relação aos parâmetros percentagem de flores e frutos raleados e peso médio dos frutos, realizaram-se análises de variância e análise de regressão polinomial, adotando-se o nível de significância de 5\%. Já para a variável diâmetro dos frutos, utilizou-se o teste Duncan para verificar diferenças entre os tratamentos, visto que os resultados encontrados na regressão polinomial não se ajustaram neste modelo de análise.

\section{RESULTADOS E DISCUSSÃO}

Os tratamentos com cianamida hidrogenada provocam alteração na percentagem de flores e de frutos raleados (figura 1) e interferem no peso (figura 2) e diâmetro dos frutos (figura 3), não alterando sólidos solúveis totais, cor e firmeza de polpa.

A testemunha $\left(0,0 \%\right.$ de $\left.\mathrm{CH}_{2} \mathrm{~N}_{2}\right)$ apresentou uma elevada queda natural de flores $(46,54 \%)$, este fenômeno pode ter ocorrido devido à utilização de plantas relativamente jovens e pouco vigorosas, aliado a ocorrência de fortes geadas. Esses fatores, segundo WESTWOOD (1982) aumentam o raleio natural de flores. A incidência de cochonilha (Pseudaulacaspis pentagona), possivelmente, tenha causado distúrbios fisiológicos nas plantas, junta- 


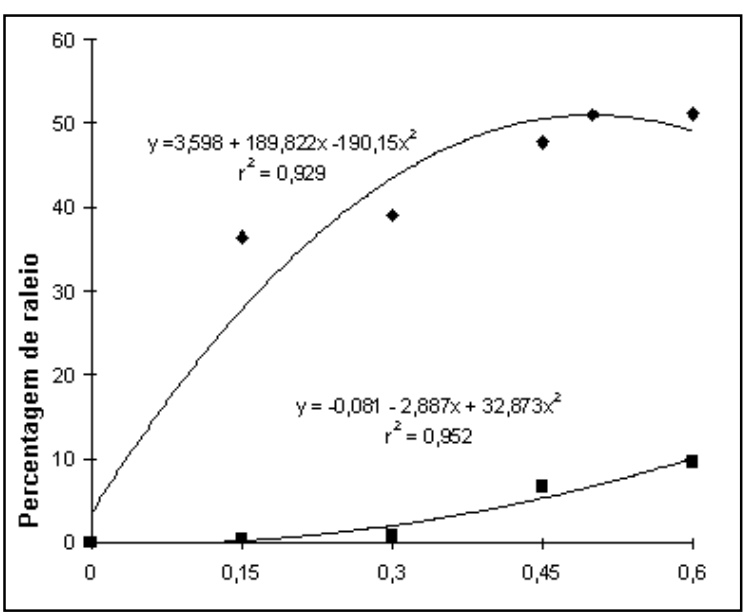

Figura 1 - Efeito de cinco concentrações de cianamida hidrogenada no raleio de flores e frutos de pessegueiros cv. Eldorado. UFPel, Pelotas, RS, 1997.

mente com a ocorrência da podridão parda (Monilinia fructicola), na fase inicial de desenvolvimento dos frutos, sendo fatores de provável contribuição para o raleio natural dos frutos. Outros fatores que podem ter atuado de forma positiva são as grandes variações de temperaturas e baixa precipitação pluvial durante a execução do experimento.

A máxima eficiência técnica para o raleio de flores foi observada com a utilização da concentração de $0,50 \%$ de $\mathrm{CH}_{2} \mathrm{~N}_{2}$ (figura 1). Este resultado assemelha-se ao encontrado por COUTINHO (1994) que, para pessegueiros do cultivar Diamante, obteve $48,62 \%$ de gemas florais raleadas, com a concentração de $0,6 \%$ de $\mathrm{CH}_{2} \mathrm{~N}_{2}$. Observou-se aumento no raleio dos frutos (figura 1) com o aumento nas concentrações de $\mathrm{CH}_{2} \mathrm{~N}_{2}$, com o valor máximo de raleio de $9,53 \%$ para a concentração de $0,6 \%$ de $\mathrm{CH}_{2} \mathrm{~N}_{2}$.

$\mathrm{O}$ peso médio dos frutos aumentou com o incremento na concentração de $\mathrm{CH}_{2} \mathrm{~N}_{2}$ (figura 2). Isto se explica, em parte, pela relação entre a menor quantidade de frutos produzidos, aumentando o peso médio destes, em função de uma maior disponibilidade de nutrientes para cada fruto.

A $\mathrm{CH}_{2} \mathrm{~N}_{2}$ proporcionou efeito linear para o diâmetro dos frutos, ou seja, o diâmetro dos frutos aumentou com o incremento das concentrações. Sem a utilização de $\mathrm{CH}_{2} \quad \mathrm{~N}_{2}$ (tratamento testemunha) apresentou um diâmetro médio dos frutos de $58,1 \mathrm{~mm}$ (figura 3), devido a maior quantidade de frutos que permaneceram na planta (figura 1). COUTINHO (1994), ao aplicar a $\mathrm{CH}_{2} \mathrm{~N}_{2}$ na cv. Diamante, quando $70 \%$ das gemas encontravam-se a partir do estádio C (ponta verde, pode observar-se o cálice), segundo a escala de FLECKINGER (1954), também observou aumento no diâmetro dos frutos,

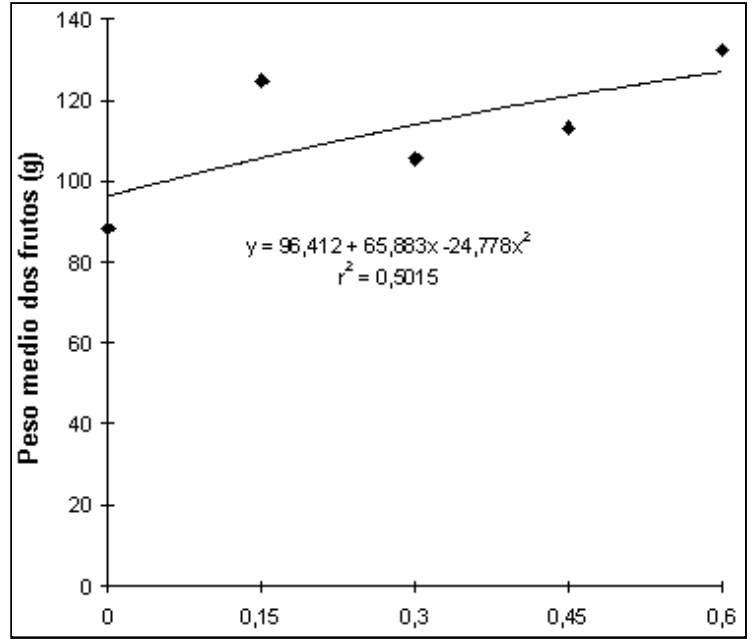

Figura 2 - Efeito de cinco concentrações de cianamida hidrogenada no peso médio dos frutos de pessegueiros cv. Eldorado. UFPel, Pelotas, RS, 1997.

com maior número de frutos nas categorias I e II (diâmetros superiores a $57 \mathrm{~mm}$ ) e diminuição da percentagem de frutos da categoria III (diâmetro inferior a $57 \mathrm{~mm}$ ).

$\mathrm{O}$ teste $\mathrm{f}$ não foi significativo para as variáveis sólidos solúveis totais, firmeza de polpa e índice de cor dos frutos. Resultados semelhantes foram obtidos por LUCCHESE et al. (1994), ao trabalhar com etefon no raleio de frutos de pessegueiro do cultivar BR1, que observaram não haver influência na qualidade da polpa dos frutos.

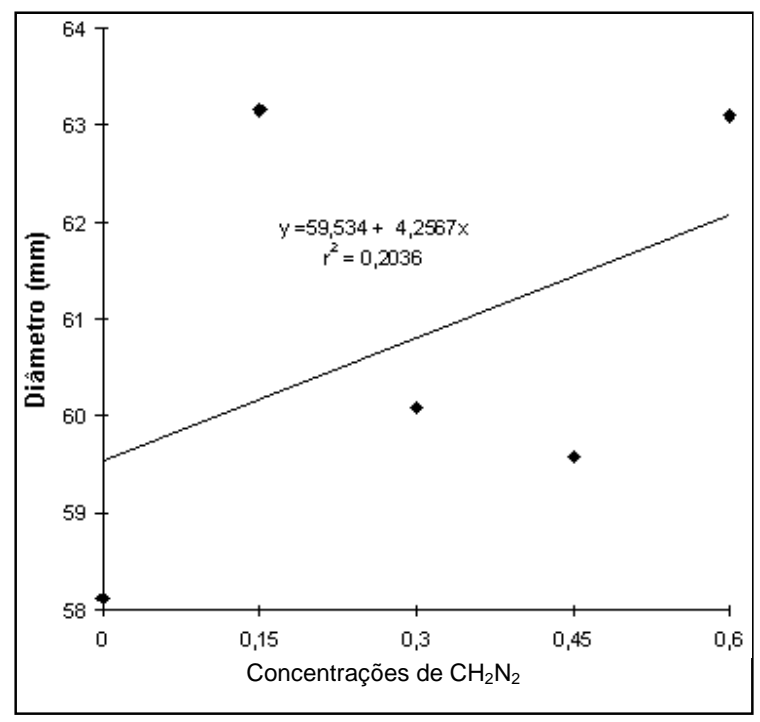

Figura 3 - Efeito de cinco concentrações de cianamida hidrogenada no diâmetro dos frutos de pessegueiros cv. Eldorado. UFPel, Pelotas, RS, 1997. 


\section{CONCLUSÕES}

$\mathrm{O}$ incremento nas concentrações de cianamida hidrogenada aumenta o raleio de flores, de plantas de pessegueiro cv. Eldorado.

$\mathrm{O}$ peso médio e o diâmetro dos frutos de pessegueiro aumentam linearmente com o incremento das concentrações de cianamida hidrogenada.

A cianamida hidrogenada não afeta a concentração de sólidos solúveis totais, a firmeza da polpa e a coloração dos frutos do pessegueiro cv. Eldorado.

\section{REFERÊNCIAS BIBLIOGRÁFICAS}

BYERS, R.E. Response of peach trees to bloom thinning. Acta Horticulturae, Wageningen,. n. 254, p. 125-133, 1989.

BYERS, R.E., LYONS, Jr. C.G., YODER, K.S. Peach and apple thining by shading and photosynthetic inibition. Journal of Horticultural Science, Ashford, v. 4, n. 60, p. 465-72, 1985.

COUTINHO, E.F. Efeito da cianamida hidrogenada no raleio químico de gemas floríferas de pessegueiro (Prunus persica (L.) Batsch) cv. Diamante. Pelotas-RS 1994. 51 p. Dissertação (Mestrado em Agronomia) - Curso de Pós-graduação em Agronomia, Universidade Federal de Pelotas, 1994.

EMPRESA BRASILEIRA DE PESQUISA AGROPECUÁRIA Centro Nacional de Fruteira de Clima Temperado. Relatório Técnico, 1980-1990. Pelotas: EMBRAPA-CNPFT, 1990. 125 p.

FLECKINGER, M. Observations récents sur l'écologie du pommier à cidre. Communication 8 . In: CONGRÈS
INTERNATIONAL DE BOTANIQUE ET D'AGRONOMIE, 1954. Paris. Note interne... Versailles: INRA, Station d'Améloration des Plantes, 1954. 14 p.

LUCCHESE, O. A., MARODIN, G.A.B., MOLINOS, P.R Raleio manual e químico de frutos em pessegueiros "BR-1" com etefon. Rev Bras Frut, Cruz das Almas, v. 16, n. 1, p. 288-294, 1994.

MAIA, M.L., AMARO, A.A., GONÇALVES, J.S., $\boldsymbol{e}$ t al. Produção e mercado de pêra e pêssego no Brasil. Informações Econômicas, São Paulo, v. 26, n. 2, p. 33-47, 1996.

MARODIN, G.A.B., MOLINOS, P.R., LUCCHESE, O.A. Raleio químico de gemas floríferas em pessegueiros "Marli" e "Diamante" com cianamida hidrogenada e óleo mineral. Rev Bras Frut, Cruz das Almas, v. 16, n. 1, p. 127-133, 1994.

MARODIN, G.A.B., LUCCHESE, O.A., MANFROI, V., et al. A cianamida hidrogenada e o óleo mineral na quebra de dormência e produção de pessegueiro da cv. "Chiripá". In: CONGRESSO BRASILEIRO DE FRUTICULTURA, 10, 1989. Fortaleza, CE. Anais... Fortaleza: SBF, 1989. 506 p. p. 415-421.

MARODIN, G.A.B., LUCCHESE, O.A., MANFROI, V. Efeito da aplicação da cianamida hidrogenada e do óleo mineral na quebra de dormência e antecipação de colheita do pessegueiro "Premier" . Rev Bras Frut, Cruz das Almas, v. 13, n. 3, p. 165-171, 1991.

SACHS, S., RHEINGANTZ, O.L.O. A influência do tamanho do pêssego no rendimento, na mão-de-obra de enlatamento, no custo da produção e na qualidade da compota. Pesquisa Agropecuária Brasileira, Brasília, v. 2, p. 437-440, 1967.

WESTWOOD, N.H. Fruticultura de zonas temperadas. Madrid: Mundi,1982. 461 p.

Ciência Rural, v. 29, n. 4, 1999. 